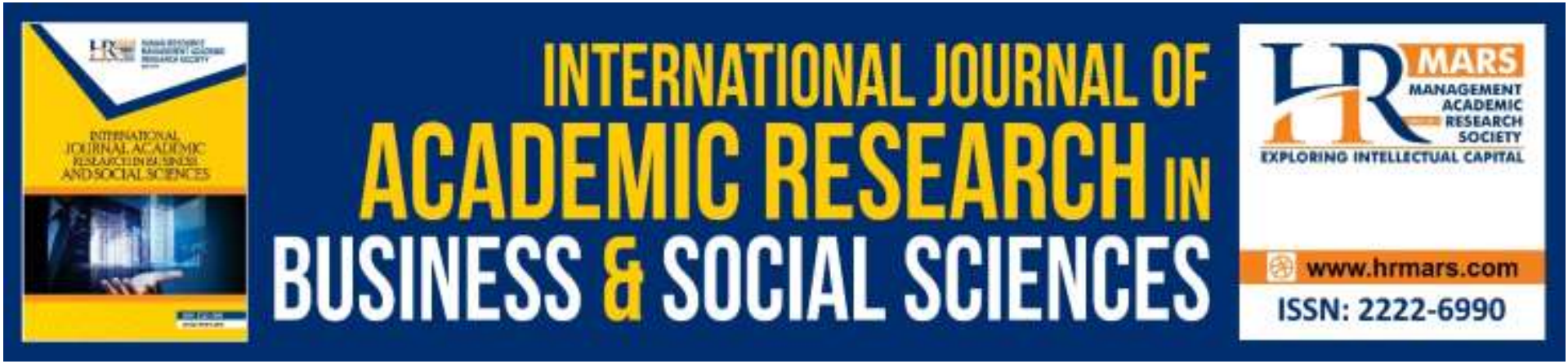

\title{
The Impact of Transformational Leadership Style on Crisis Management in Yemen Organizations
}

Mohammed Ali Saleh Alkhawlani, Abdul Manaf bin Bohari, Jauriyah binti Shamsuddin

To Link this Article: http://dx.doi.org/10.6007/IJARBSS/v9-i9/6274

DOI: $10.6007 /$ IJARBSS/v9-i9/6274

Received: 07 June 2019, Revised: 14 July 2019, Accepted: 30 August 2019

Published Online: 23 September 2019

In-Text Citation: (Alkhawlani, Bohari, \& Shamsuddin, 2019)

To Cite this Article: Alkhawlani, M. A. S., Bohari, A. M. bin, \& Shamsuddin, J. binti. (2019). The Impact of Transformational Leadership Style on Crisis Management in Yemen Organizations. International Journal of Academic Research in Business and Social Sciences, 9(9), 127-139.

\section{Copyright: (C) 2019 The Author(s)}

Published by Human Resource Management Academic Research Society (www.hrmars.com)

This article is published under the Creative Commons Attribution (CC BY 4.0) license. Anyone may reproduce, distribute, translate and create derivative works of this article (for both commercial and non-commercial purposes), subject to full attribution to the original publication and authors. The full terms of this license may be seen at: http://creativecommons.org/licences/by/4.0/legalcode

\section{Vol. 9, No. 9, 2019, Pg. 127 - 139}

Full Terms \& Conditions of access and use can be found at http://hrmars.com/index.php/pages/detail/publication-ethics 


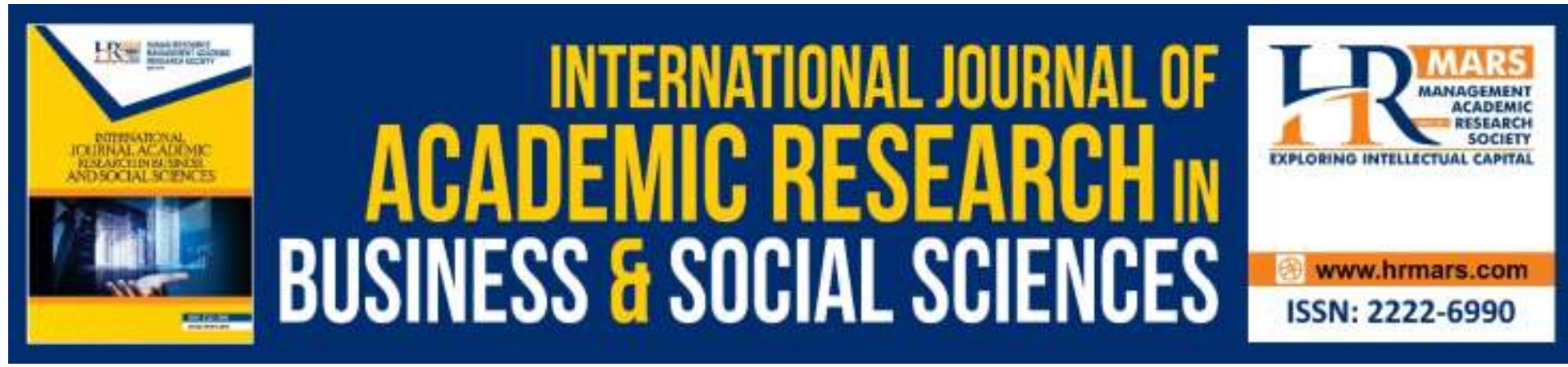

\title{
The Impact of Transformational Leadership Style on Crisis Management in Yemen Organizations
}

\section{Mohammed Ali Saleh Alkhawlani, Prof. Abdul Manaf bin Bohari, Dr. Jauriyah binti Shamsuddin}

Senior Lecturer, School of Business Management, University Utara Malaysia Email: Alkhowlani2000@yahoo.com,manafdr@uum.edu.my,jauriyah@uum.edu.my

\begin{abstract}
This study aims to examine the impact of transformational leadership style on crisis management and to examine the moderating effect of manager's crisis experience on the relationship between transformational leadership style and crisis management in Yemen organizations. Data was collected from 239 large private organizations in Yemen, through the self-administered questionnaire procedure. Partial Least Squares-Structural Equation Modelling (PLS-SEM) was employed in the data analysis. The result indicates that transformational leadership style has a significant positive influence on crisis management. The result also reveals that the manager's crisis experience moderate the relationship between the transformational leadership style and crisis management. In practical terms, the results of the current study offer several implications for managers regarding the importance role of the factors enhancing crisis management in Yemen organizations. Moreover, leader with a prior crisis experience is more capable to handle the crisis situation. The limitation of the current study and the recommendation for the future study are highlighted.
\end{abstract}

Keywords: Crisis Management, Manager's Crisis Experience, Transformational leadership

\section{Introduction}

Crisis is an unexpected, dramatic, and unprecedented event that forces an organization into chaos and may destroy the organization (Prewitt, Weil, \& McClure, 2011). However, the 2011 crisis in Yemen adversely impacted the employment, large, small and medium-sized enterprises (SMEs), product and food prices and basic services in public and private organizations in Yemen. It is estimated that 15 percent of all private-sector workers and 30 40 percent of factory workers lost their jobs, while the salary of most employees was reduced by around 20 percent and unpaid leave was extended by up to six months (UNDP, 2013). In such circumstance, crisis management is essential to minimize economic losses and to ensure companies' survival (Sfakianaki, Iliadis, \& Zafeiris, 2015). Effective crisis management can minimize the impact of the crisis on organizations (Spillan, Parnell, \& de Mayolo, 2011). A review of the previous literature has revealed that in times of crisis, effective leaders have taken crucial actions to reduce the concerns of the organization members and inform them 
how the crisis could affect them (Yukl, 2010). DuBrin (2013) stressed that to mitigate the consequences of the crisis, transformational leadership is the best choice, and it works perfectly in the immediate and post-crisis stages. Likewise, in a crisis situation, transformational leadership has been identified by researchers as the most comprehensive and effective approach. Transformational leadership style has been extensively and intensely studied, whereas transformational leadership style during the crisis still needs to be explored (Alkhawlani, Bin Bohari, Haderi, Ahmed, \& Rahim, 2016; Alkhawlani, Bin Bohari,\& Shamsuddin, 2019). Research on the importance of the transformational leadership during a crisis situation, are still scant, according to Pillai (2013), who advocated that there is still much to learn about the effectiveness of transformational leadership across cultures during a crisis situation. However, crisis experience enhances the crisis leader's sense-making abilities of the situation, and their learned lessons contribute to a more confident. Thus, manager's prior experience in a crisis situation assit to understand approach of crisis readiness (Cronin, 2015). Many studies mentioned that leader experience of a crisis makes the organization to be better prepared for future crises (Kovoor-Misara, 1996; Rousaki and Alcott, 2006).

According to the discussion above, there is a lack of empirical studies that have investigated the important factors affect crisis management, especially during crisis confrontation, such as leadership style and the role of manager's crisis experience. The gap is excited and justifies the need for empirical studies to be conducted while the Yemen organizations are experienced the crisis. Therefore, this study aimed to examine the impact of transformational leadership style on crisis management and to examine the moderating effect of manager's crisis experience on the relationship between transformational leadership style and crisis management in Yemen organizations.

\section{Literature Review}

\section{Transformational leadership}

It is a fact that crisis and leadership are inextricably related. Every follower looks up to the leaders during a crisis situation and expects them to do something (Zhang, Jia, \& Gu, 2012). In a crisis situation, transformational leadership can lead the organization towards a better future by encouraging the organization's members to express their ideas on how to cope with the crisis and work collaboratively, to either manage or avoid crisis situations (Harwati, 2013). Transformational leadership can be defined according to Bass and Avolio (1994) as "a set of interrelated behaviors, including idealized influence, inspirational motivation, intellectual stimulation and individual consideration" (Dust, Resick, and Mawritz, 2014). The model of transformational leadership was developed by Bass and Avolio (1994), including four primary factors: "idealized influence, individualized consideration, intellectual stimulation and inspirational motivation". Transformational leadership components are explained in details as follow.

- Idealized influence: Instilling pride and respect for the leader; shares a vision and sense of mission. Representation of a trustworthy leader and acts as a role model for the follower.

- Individualized consideration: Leaders treat each subordinate differently according to his or her particular needs and capabilities. 
- Intellectual stimulation: Leaders "stimulate followers' efforts to be innovative and creative by questioning assumptions, reframing problems, and approaching old situations in new ways".

- Inspirational motivation: Leaders "behave in ways that motivate and inspire those around them by providing meaning and challenge to their followers' work".

Source: Rowold and Heinitz (2007)

Transformational leadership has been studied extensively; several studies have reported that the transformational leadership style has been associated with numerous variables, such as organizational learning (Mirkamali, Thani, \& Alami, 2011); employee effectiveness (Srithongrung, 2011); creative flexibility (Sharma, Nagar, \& Pathak, 2012); communication competency (Çetin, Karabay, \& Efe, 2012); leadership effectiveness (Zhang et al., 2012); and employees' job satisfaction (Munir, Rahman, Malik, \& Ma'amor, 2012). Only limited empirical studies have focused on the relationship between transformational leadership and crisis management, such as Hasan and Rjoub (2017), who examined the association between leadership styles and crisis management in the Ministry of Planning in Erbil, Iraq; the findings reveal that transformational leaders can predict crisis management. Similarly, Sarkar and Ray (2015) examined the role of transformational leadership style in crisis management, targeting the correctional officers of the West Bengal organizations and found that transformational leadership style has a significant association with crisis management. In addition, previous research has mentioned the requirement for more research on the association between transformational leadership and crisis management ( Alkhawlani, et al., 2019; Cho \& Tseng, 2009; Pillai, 2013; Zhang et al., 2012). Thus, responding to the recommendation of the previous research, this study hypothesized that:

H1: There is a positive relationship between transformational leadership and crisis management.

\section{Manager's Crisis Experience}

Crisis experience can be defined as knowledge and the skills that individual or organization gained, in particular, situation, specifically, during crisis situation (Alkhawlani, et al., 2019). In literature, only very few studies regarding crisis experience such as Reynolds (2009) found a positive relationship between crisis experience and effective communication but no relationship between crisis experience and transformational leader behavior. In addition, Carmeli and Schaubroeck (2008) assumed that crisis experience would be positively associated with crisis-preparedness, but the results of the study didn't support the hypothesis. A further study conducted by Guth (1995) argued that there is a relationship between organizational size and crisis experience. Cronin and Parry (2014) explained that leadership had prior crisis experience is more confidence, and it being reflective in their decision making. Moreover, Rousaki and Alcott (2006) argued that prior experience of the crisis is associated with increasing crisis readiness. In the same line, Schwarz and Pforr (2011) confirmed the association between crisis experience and crisis preparedness. As discussed above all studies mentioned the important role of crisis experience in enhancing crisis management, but no study examines categorical variable manager's crisis experience as moderator effect in relationship between transformational leadership, and crisis management. Therefore, this study hypothesized that: 
H2: There is a positive relationship between manager's crisis experience and crisis management.

H3: Manager's crisis experience moderates the relationship between transformational leadership style and crisis management.

\section{Crisis management}

Crisis has a harmful result on the organization stability that leads to the serious question, whether or not organizations would be able to continue after crisis situation (Seeger, Ulmer, Novak, \& Sellnow, 2005). Therefore, crisis management has been established to efficiently and effectively prevent and reduce the negative consequences of the crisis situation. Crisis management has been extensively studied during the past three decades and defined by many different authors. There is no single definition that is commonly agreed upon the term of crisis management (Coombs, 2007). Santana (2004) defined crisis-management as, "an ongoing integrated and comprehensive effort that organizations effectively put into place in an attempt to first and foremost understand and prevent crisis and to effectively manage those that occur, taking into account in each and every step of their planning and training activities the interest of their stakeholders. Numerous models of crisis management have been developed by researchers, such as Coombs (2007); Cronstedt (2002); Fink (1986); Jaques (2007); Loosemore and Teo (2000); Myers (1993); Smith (1990). Mitroff, Pauchant, and Shrivastava (1988); Mitroff, Shrivastava, and Udwadia (1987) developed a crisis management model, which includes five mechanisms that need to be in place: "signal detection; prevention/preparation; damage containment (limitation); recovery and learning". This model represents the holistic crisis life cycle that stimulates action throughout the crisis, and not only during the pre-crisis or post-crisis period, like other models. However, previous studies have identified the factors influencing crisis management, such as long-term strategy, internal and external strategic orientation and crisis readiness (Mostafa, Sheaff, Morris, and Ingham (2004); organization size, job level crisis experience and crisis readiness (Rousaki and Alcott (2006); management experience and crisis readiness (Parnell, Koseoglu, and Spillan (2010); organizational type, organization size, organization age and crisis preparedness (Ritchie, Bentley, Koruth, and Wang (2011); and strategy innovation, strategy on low costs and crisis readiness (Spillan et al., 2011). Accordingly, no study accommodates transformational leadership, manager's crisis experience and crisis-management stages. Therefore, this study examined the effect of those factors on crisis management.

\section{Methodology}

The present paper used the quantitative method and was conducted in Yemen. The target population is large private organizations that registered under the Ministry of Industry and Trade in Yemen. The top management is representative of the population of the current study. These respondents met the requirements of the study by providing valid and accurate views of their organization. The Krejcie and Morgan (1970) table was used for determining the sample size of the present study, which is 281 large private organizations in Yemen. Simple random sampling was used to select the respondents. Out of the 281, only 239 questionnaires were returned. The questionnaire was adapted from previous studies (Alkhawlani, et al., 2016; Sadeghi and Pihie, 2012). The instrument had been validated by earlier researchers and deemed to be ideal for the current study. A five-point Likert scale was used to measure the two variables, namely transformational leadership and crisis management. The manager's 
crisis experience was examined as a categorical variable. A cover letter attached to each questionnaire explained the objective of the survey and assured the respondents of the confidentiality of their responses.

\section{Results}

The PLS-SEM (Partial Least Squares-Structural Equation Modeling) approach was employed in data analysis in this study. Hair, Hult, Ringle, and Sarstedt (2017) recommended that PLS analysis involves two stages for reporting the results: the assessment of the measurement model in the first stage; and the assessment of the structural model in the second stage.

\section{Assessment of Measurement Model}

According to Hair et al. (2017), the key criteria used to evaluate the measurement model are internal consistency reliability, convergent and discriminant validity. To evaluate the convergent validity of reflective constructs, researchers consider the outer loadings of the indicators and the average variance extracted (AVE). The recommended values for the outer loadings, according to Hair, Black, Babin, Anderson, and Tatham (2006), are $\geq 0.5$, and preferably $\geq 0.70$., the average variance extracted (AVE) should be $>0.5$, and the composite reliability $(C R)$ should be $>0.7$. The researcher conceptualized transformational leadership style and crisis management as second-order constructs, which is consistent with theoretical concept and supported by Hair, Hult, Ringle, and Sarstedt (2014), who recommended utilizing second-order construct to reduce the number of relationships in the model. Thus, the method suggested according to Hair et al. (2017) in PLS-SEM is the repeated indicator approach for the second-order construct. Table 4.1 shows the results of convergent validity which exceeds the recommended values and representative sufficient convergent validity. 
INTERNATIONAL JOURNAL OF ACADEMIC RESEARCH IN BUSINESS AND SOCIAL SCIENCES

Vol. 9, No. 9, September, 2019, E-ISSN: 2222-6990 @ 2019 HRMARS

Table 4.1

Convergent Validity First \& second Order

\begin{tabular}{|c|c|c|c|c|c|}
\hline \multicolumn{6}{|l|}{ Constructs } \\
\hline Second Order Construct & $\begin{array}{l}\text { First Order } \\
\text { Constructs }\end{array}$ & Item & Loadings & AVE & CR \\
\hline \multirow[t]{21}{*}{ TFLS } & & TFLII & 0.792 & 0.604 & 0.858 \\
\hline & & TFLIM & 0.628 & & \\
\hline & & TFLIS & 0.821 & & \\
\hline & & TFLIC & 0.849 & & \\
\hline & TFLII & TFLIIA3 & 0.608 & 0.670 & 0.909 \\
\hline & & TFLIIA4 & 0.872 & & \\
\hline & & TFLIIB5 & 0.867 & & \\
\hline & & TFLIIB6 & 0.885 & & \\
\hline & & TFLIIB7 & 0.829 & & \\
\hline & TFLIM & TFLIM10 & 0.904 & 0.798 & 0.940 \\
\hline & & TFLIM11 & 0.913 & & \\
\hline & & TFLIM12 & 0.911 & & \\
\hline & & TFLIM9 & 0.843 & & \\
\hline & TFLIS & TFLIS13 & 0.923 & 0.825 & 0.950 \\
\hline & & TFLIS14 & 0.915 & & \\
\hline & & TFLIS15 & 0.933 & & \\
\hline & & TFLIS16 & 0.861 & & \\
\hline & TFLIC & TFLIC17 & 0.925 & 0.836 & 0.953 \\
\hline & & TFLIC18 & 0.914 & & \\
\hline & & TFLIC19 & 0.933 & & \\
\hline & & TFLIC20 & 0.884 & & \\
\hline \multirow[t]{30}{*}{ CM } & & CMSD & 0.751 & 0.583 & 0.874 \\
\hline & & CMPP & 0.852 & & \\
\hline & & CMDC & 0.681 & & \\
\hline & & CMBR & 0.775 & & \\
\hline & & CMLR & 0.749 & & \\
\hline & CMSD & CMSD1 & 0.901 & 0.751 & 0.923 \\
\hline & & CMSD2 & 0.900 & & \\
\hline & & CMSD4 & 0.879 & & \\
\hline & & CMSD5 & 0.782 & & \\
\hline & CMPP & CMPP10 & 0.879 & 0.753 & 0.955 \\
\hline & & CMPP11 & 0.885 & & \\
\hline & & CMPP12 & 0.859 & & \\
\hline & & CMPP13 & 0.812 & & \\
\hline & & CMPP7 & 0.858 & & \\
\hline & & CMPP8 & 0.877 & & \\
\hline & & CMPPg & 0.902 & & \\
\hline & CMDC & CMDC15 & 0.848 & 0.763 & 0.951 \\
\hline & & CMDC16 & 0.869 & & \\
\hline & & CMDC17 & 0.878 & & \\
\hline & & CMDC18 & 0.900 & & \\
\hline & & CMDC19 & 0.886 & & \\
\hline & & CMDC20 & 0.860 & & \\
\hline & CMBR & CMBR22 & 0.908 & 0.805 & 0.943 \\
\hline & & CMBR23 & 0.899 & & \\
\hline & & CMBR24 & 0.889 & & \\
\hline & & CMBR25 & 0.892 & & \\
\hline & CMLR & CMLR26 & 0.913 & 0.818 & 0.947 \\
\hline & & CMLR27 & 0.881 & & \\
\hline & & CMLR28 & 0.920 & & \\
\hline & & CMDC29 & 0.904 & & \\
\hline
\end{tabular}

Notes: $\mathrm{CM}=$ crisis management $(\mathrm{CMSD}=$ signal detection, $\mathrm{CMPP}=$ preparation \& prevention, $\mathrm{CMBR}=$ Business recovery, $\mathrm{CMDC}=$ Damage containment, $\mathrm{CMLR}=$ Learning); TFLS= transformational leadership $(\mathrm{TFLSIC}=$ Individualized consideration, TFLSII $=$ Idealized 
influence, TFLSIM = Inspirational motivation, TFLSIS= Intellectual stimulation, AVE = Average Variance Extracted $\mathrm{CR}=$ Composite Reliability

The second criteria to examine the measurement model is discriminant validity. There are several methods to calculate discriminant validity; one of the highly recommended methods is related to the Fornell and Larcker (1981) criterion. It compares the square root of the AVE values with the latent variable correlations. Specifically, the square root of each construct's AVE should be greater than its highest correlation with any other construct. This criterion is considered as a more conservative method to assess discriminant validity (Hair et al., 2014). Table 4.2 shows the results of the Fornell-Larcker criterion, which achieved the required criteria.

Table 4.2

Fornell-Larcker Criterion for second-order constructs

\begin{tabular}{lcc}
\hline & $\mathrm{CM}$ & $\mathrm{TFL}$ \\
\hline $\mathrm{CM}$ & $\mathbf{0 . 7 6 4}$ & \\
TFLS & 0.375 & $\mathbf{0 . 7 7 7}$ \\
\hline
\end{tabular}

Notes, $\mathrm{TFLS}=$ transformational leadership style, and $\mathrm{CM}=$ crisis management

\section{Assessment of PLS-SEM Model Results}

To assess the structural model, Hair et al. (2017); Valérie (2012), recommended that the primary evaluation criteria for PLS-SEM results are the coefficients of determination $\left(R^{2}\right.$ values) as well as the size and significance of the path coefficients. The $f^{2}$ effect sizes, predictive relevance $\left(Q^{2}\right)$, and the $q^{2}$ effect sizes give additional insights into the quality of the PLS path model estimations, followed by the mediating effect. However, as the endogenous variable constructed as second-order, Ringle, Sarstedt, and Straub (2012) recommender to follow the two-stage approach instead of repeated indicator approach during the assessment of the structural model because if the second-order variable is used as an endogenous construct, almost all of its variance is explained by its indicators. The result of bootstrapping illustrated in Table 4.3 and Figure 4.1.

Table 4.3

Results of Hypotheses Testing

\begin{tabular}{ccccccc}
\hline Hyp & Relationship & Beta & SE & $\begin{array}{c}\text { T- } \\
\text { value }\end{array}$ & $\begin{array}{c}\text { P- } \\
\text { value }\end{array}$ & Findings \\
\cline { 2 - 6 } H1 & TFLS -> CM & 0.132 & 0.07 & 5.303 & 0.03 & Supported \\
H2 & MCE -> CM & 0.38 & 0.07 & 1.887 & 0.00 & Supported \\
\hline
\end{tabular}

Notes, TFLS= transformational leadership style, MCE= Manager's Crisis Experience and $\mathrm{CM}=$ crisis management 


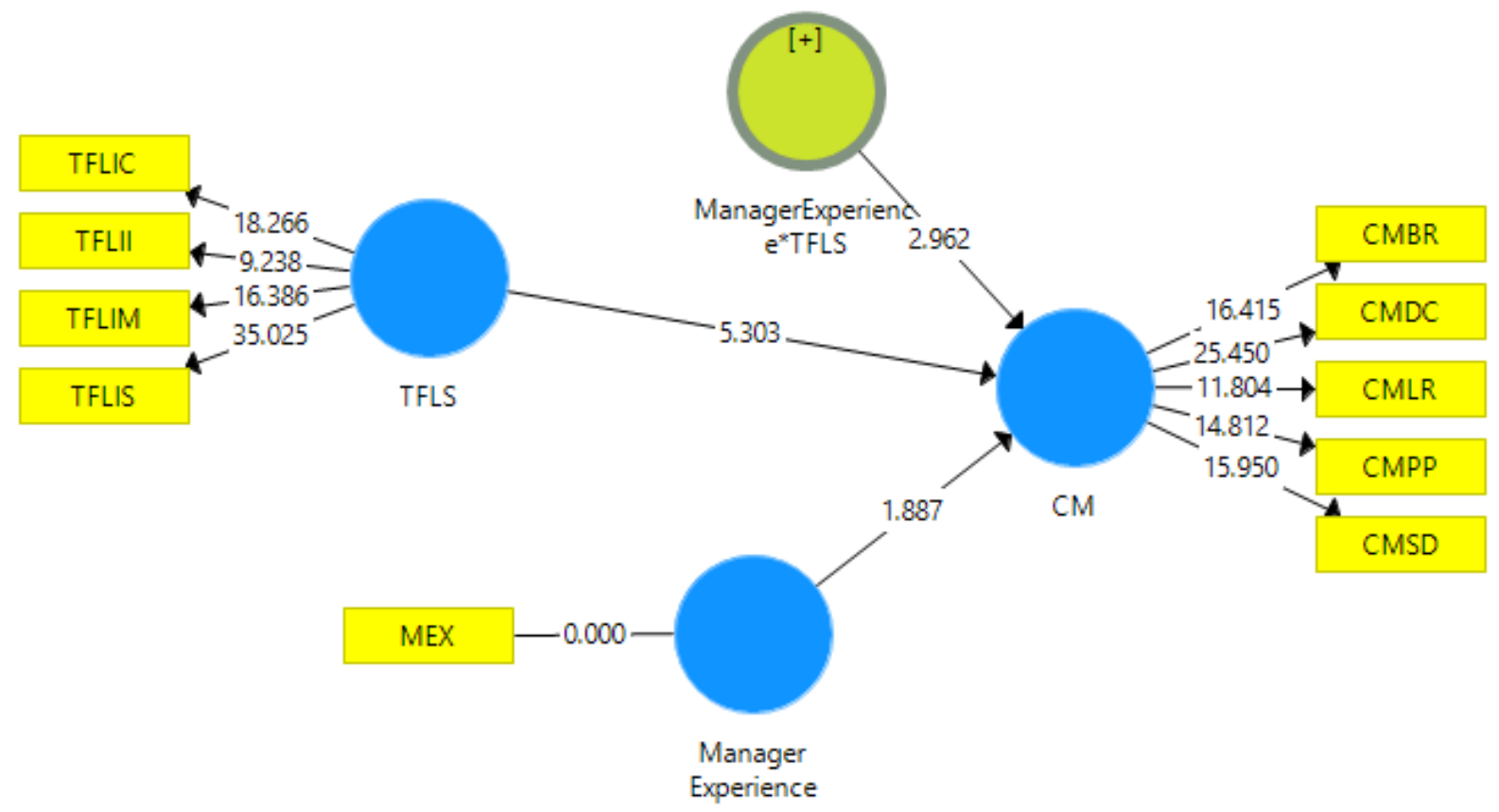

Figure 4.1

The structural model with moderator

Table 4.3 shows the results of hypotheses testing. Specifically, the result of hypothesis one $(\mathrm{H} 1)$ shows that transformational leadership style is positively related to crisis management $(\beta=0.132, T=5.303, P=0.03)$. Therefore, hypothesis one $(H 1)$ is supported. The result of hypothesis two $(\mathrm{H} 2)$ indicates a significant positive relationship between manager's crisis experience and crisis management $(\beta=0.38, T=1.887, P=0.000)$. Therefore, hypothesis two $(\mathrm{H} 2)$ is also supported.

Table 4.4.

Moderator result

\begin{tabular}{lllllll}
\hline Hyp & Relationship & Beta & SE & $\begin{array}{c}\text { T- } \\
\text { value }\end{array}$ & $\begin{array}{c}\text { P- } \\
\text { value }\end{array}$ & Findings \\
\hline H3 & $\begin{array}{l}\text { ManagerExperience*TFLS } \\
->\text { CM }\end{array}$ & 0.182 & 0.061 & 2.962 & 0.002 & Supported \\
\hline
\end{tabular}

Notes, TFLS $=$ transformational leadership style, MCE $=$ Manager Crisis Experience and $\mathrm{CM}=$ crisis management

Next, we tested the moderation effect of manger's crisis experience in the relationship between transformational leadership and crisis management by conducting the bootstrapping procedure, as suggested by Hair, Black, and Babin (2010). The results of hypothesis three (3) illustrated in Figure 4.1 and Table 4.4. The finding indicated the existing of the positive moderating effect of manager's crisis experience on the relationship between 
transformational leadership and crisis management, with the result of $(\beta=0.182, P=0.002$, $\mathrm{T}=2.962)$. Therefore, hypothesis three(H3) is supported as well.

\section{Discussion \& Conclusion \\ Discussion}

This study aims to examine the impact of transformational leadership style on crisis management and to examine the moderating effect of manager's crisis experience on the relationship between transformational leadership style and crisis management in Yemen organizations. The result in Table 4.3 explained that for every unit increase in transformational leadership, there is an expected increase of 0.132 in crisis management. Further, transformational leadership style as idealized influence, consider the leaders to become a role model for the followers, whether they exhibit certain personal characteristics or "charisma" often seen as being high on morality, trust, integrity, honesty and purpose. Also, leaders tend to be admired, respected and trusted; so, followers determine and follow their leader's instructions. This result is consistent with previous studies, such as Alkhawlani, et al. (2019); Cho and Tseng (2009); Hasan and Rjoub (2017); Zhang et al. (2012).

The second research objective is to determine the relationship between manger's crisis experience and crisis management which is confirmed by the result in Table 4.3 ( $\beta=0.38, T$ value $=1.887$ ), which indicated a significant positive relationship. This finding is consistent with the previous studies, such as Cronin (2015); and Schwarz \& Pforr (2011). Also, supported by many studies which mentioned that manager with prior crisis experience is able to handle the crisis in a proper way (Kovoor-Misra, 1996; Rousaki and Alcott's, 2006).

The third research objective of this study is considered as one of the main contributions of the current study, which is to examine moderating effect of manager's crisis experience on the relationship between transformational leadership and crisis management. According to the result shown in Table 4.4, manger's crisis experience enhances the relationship between transformational leadership and crisis management. The result of the study emphasizes that the moderating effect of crisis experiences is existed and would improve the handling of the crisis and lead to better control and reducing the crisis consequences.

\section{Limitations}

The limitation of the current study related to the generalizability; the findings of this study cannot be generalized to a wider context across cultures of other countries since the data collected for this study is limited to Yemeni large private organizations. Different cultures and different educational environments may furnish different impacts of transformational leadership style on crisis management. Future research is recommended to focus on the mediating and moderating roles of the factors that influence crisis management during a crisis situation.

\section{Conclusion}

The current study reveals that transformational leadership is important factors that can enhance crisis management during the confrontation of the crisis situation. In addition, the moderating effect of manager's crisis experience approved to enhance the relationship between transformational leadership and crisis management, which could expand the body of knowledge in the crisis management field. Therefore, this study has achieved its objectives, 
and it is important for the leaders in the large private organizations in Yemen to employ the results of this study in order to respond more effectively and efficiently to the crisis.

\section{References}

Alkhawlani, M. A. S., Bohari, B. A. M., Haderi, S. M. A., Ahmed, F. B., \& Rahim, N. F. A. (2016). Charisma Leadership an Important Determinant for the Crisis Management. International Journal of Business and Social Science, 7(9), 126-136.

Alkhawlani, M. A. S., Bohari, B. A. M., Shamsuddin, B. J. (2019). Factors that Influence Crisis Management in Yemen Organizations: The Mediating Effect of Decision- making Styles. International Journal of Innovation, Creativity and Change, 5(2), 11-34.

Bass, B. M., \& Avolio, B. J. (1994). Improving organizational effectiveness through transformational leadership: Thousand Oaks, California: SAGE Publications, Inc.

Carmeli, A., \& Schaubroeck, J. (2008). Organisational crisis-preparedness: the importance of learning from failures. Long Range Planning, 41(2), 177-196.

Çetin, M., Karabay, M. E., \& Efe, M. N. (2012). The Effects of Leadership Styles and the Communication Competency of Bank Managers on the Employee's Job Satisfaction: The Case of Turkish Banks. Procedia - Social and Behavioral Sciences, 58, 227-235.

Cho, S., \& Tseng, P. F. (2009). Leadership in the 2008 financial crisis. (Master Thesis), Jönköping University, Jönköping, Sweden.

Coombs, W. T. (2007). Protecting Organization Reputations During a Crisis: The Development and Application of Situational Crisis Communication Theory. Corporate Reputation Review, 10(3), 163-176.

Cronin, J., \& Parry, K. (2014). How does crisis leadership influence effective crisis readiness (CR)? Tourism crisis and disaster management in the Asia-Pacific, 1, 62.

Cronin, J. K. (2015). Empowering Readiness: Influencing Crisis Management Success Outcomes. (Doctor of Philosophy). Bond University, Australia,

Cronstedt, M. (2002). Prevention, preparedness, response, recovery-an outdated concept? Australian Journal of Emergency Management, 17(2), 10.

DuBrin, A. J. (2013). Personal attributes and behaviors of effective crisis leaders. Northampton, MA, USA: Edward Elgar

Dust, S. B., Resick, C. J., \& Mawritz, M. B. (2014). Transformational leadership, psychological empowerment, and the moderating role of mechanistic-organic contexts. Journal of Organizational Behavior, 35(3), 413-433.

Fink, S. (1986). Crisis management: Planning for the inevitable: New York, NY, American Management Association.

Fornell, C., \& Larcker, D. F. (1981). Evaluating Structural Equation Models with Unobservable Variables and Measurement Error. Journal of Marketing Research, 18(1), 39-50. doi:10.2307/3151312

Guth, D. W. (1995). Organizational crisis experience and public relations roles. Public Relations Review, 21(2), 123-136.

Hair, J. F., Black, W. C., \& Babin, B. J. (2010). Multivariate Data Analysis: A Global Perspective: Pearson Education.

Hair, J. F., Black, W. C., Babin, B. J., Anderson, R. E., \& Tatham, R. L. (2006). Multivariate data analysis . Uppersaddle River. In: NJ: Pearson Prentice Hall.

Hair, J. F., Hult, G. T. M., Ringle, C., \& Sarstedt, M. (2014). A primer on partial least squares structural equation modeling (PLS-SEM): Sage Publications. 
Hair, J. F., Hult, G. T. M., Ringle, C., \& Sarstedt, M. (2017). A primer on partial least squares structural equation modeling (PLS-SEM): Sage Publications.

Harwati, L. N. (2013). Crisis management: Determining specific strategies and leadership style for effective outcomes. ASIAN JOURNAL OF MANAGEMENT SCIENCES AND EDUCATION, 2(2), 1-12.

Hasan, A., \& Rjoub, H. (2017). The Role of Effective Leadership Styles in Crisis Management: A Study of Erbil, Iraq. International Journal of Economics, Commerce \& Management, $V(4), 107-121$.

Huang, Y. H. (2008). Trust and Relational Commitment in Corporate Crises: The Effects of Crisis Communicative Strategy and Form of Crisis Response. Journal of Public Relations Research, 20(3), 297-327.

Jaques, T. (2007). Issue management and crisis management: An integrated, non-linear, relational construct. Public Relations Review, 33(2), 147-157.

Kovoor-Misara, S. (1996). Moving toward crisis preparedness: Factors that motivate organizations. Technological Forecasting and Social Change, 53(2), 169-183.

Krejcie, R. V., \& Morgan, D. W. (1970). Determining sample size for research activities. Educational and Psychological Measurement, 30(3), 607-610.

Loosemore, M., \& Teo, M. (2000). Crisis preparedness of construction companies. Journal of Management in Engineering, 16(5), 60-65.

Mirkamali, S. M., Thani, F. N., \& Alami, F. (2011). Examining the role of transformational leadership and job satisfaction in the organizational learning of an automotive manufacturing company. Procedia-Social and Behavioral Sciences, 29, 139-148.

Mitroff, I. I., Pauchant, T. C., \& Shrivastava, P. (1988). The structure of man-made organizational crises: Conceptual and empirical issues in the development of a general theory of crisis management. Technological Forecasting and Social Change, 33(2), 83107.

Mitroff, I. I., Shrivastava, P., \& Udwadia, F. E. (1987). Effective crisis management. The Academy of Management Executive (1987-1989), 283-292.

Mostafa, M. M., Sheaff, R., Morris, M., \& Ingham, V. (2004). Strategic preparation for crisis management in hospitals: empirical evidence from Egypt. Disaster Prevention and Management: An International Journal, 13(5), 399-408.

Munir, R. I. S., Rahman, R. A., Malik, A. M. A., \& Ma'amor, H. (2012). Relationship between Transformational Leadership and Employees' Job Satisfaction among the Academic Staff. Procedia - Social and Behavioral Sciences, 65, 885-890.

Myers, K. N. (1993). Total Contingency Planning for Diasters: Managing Risk... Minimizing Loss... Ensuring Business Continuity: John Wiley \& Sons, Inc.

Parnell, J. A., Koseoglu, M. A., \& Spillan, J. E. (2010). Crisis readiness in Turkey and the United States. Journal of Contingencies and Crisis Management, 18(2), 108-116.

Pillai, R. (2013). Transformational leadership for crisis management.

Prewitt, J. E., Weil, R., \& McClure, A. Q. (2011). Crisis Leadership-An Organizational Opportunity. Australian Journal of Business and Management Research, 1(6), 60.

Reynolds, B. J. (2009). An exploration of crisis experience and training as they relate to transformational leadership and rhetorical sensitivity among US public health officials. Capella University,

Ringle, C. M., Sarstedt, M., \& Straub, D. (2012). A critical look at the use of PLS-SEM in MIS Quarterly. 
Ritchie, B. W., Bentley, G., Koruth, T., \& Wang, J. (2011). Proactive Crisis Planning: Lessons for the Accommodation Industry. Scandinavian Journal of Hospitality and Tourism, 11(3), 367-386.

Rousaki, B., \& Alcott, P. (2006). Exploring the crisis readiness perceptions of hotel managers in the UK. Tourism and Hospitality Research, 7(1), 27-38.

Rowold, J., \& Heinitz, K. (2007). Transformational and charismatic leadership: Assessing the convergent, divergent and criterion validity of the MLQ and the CKS. The Leadership Quarterly, 18(2), 121-133.

Santana, G. (2004). Crisis Management and Tourism. Journal of Travel \& Tourism Marketing, 15(4), 299-321.

Sarkar, M., \& Ray, A. (2015). Transformational leadership style as a predictor of crisis management skill: a study on correctional officers of west Bengal. Journal of Contemporary Psychological Research, 2(2), 29-40.

Schwarz, A., \& Pforr, F. (2011). The crisis communication preparedness of nonprofit organizations: The case of German interest groups. Public Relations Review, 37(1), 6870.

Seeger, M. W., Ulmer, R. R., Novak, J. M., \& Sellnow, T. (2005). Post-crisis discourse and organizational change, failure and renewal. Journal of Organizational Change Management, 18(1), 78-95.

Sfakianaki, E., Iliadis, T., \& Zafeiris, E. (2015). Crisis management under an economic recession in construction: the Greek case. International Journal of Management and Decision Making, 14(4), 373-389.

Sharma, P., Nagar, P., \& Pathak, S. (2012). Impact of Transformational Leadership on Creative Flexibility of Engineers in India. Procedia-Social and Behavioral Sciences, 57, 555-559.

Smith, D. (1990). Beyond contingency planning: towards a model of crisis management. Industrial Crisis Quarterly, 4(4), 263-275.

Spillan, J. E., Parnell, J. A., \& Mayolo, D. C. A. (2011). Exploring crisis readiness in Peru. Journal of International Business and Economy, 12(1), 57-83.

Srithongrung, A. (2011). The causal relationships among transformational leadership, organizational commitment, and employee effectiveness. International Journal of Public Administration, 34(6), 376-388.

UNDP. (2013). Multi-dimensional Livelihoods Assessment in Conflict Affected Areas. Retrieved from

http://www.ye.undp.org/content/yemen/en/home/library/crisis_prevention_and_r ecovery/multidimensional-livelihoods-assessment-in-conflict-areas-in-yem.html

Valérie, F. (2012). (Re) discovering the PLS approach in management science. M@n@ gement, 15(1).

Yukl, G. A. (2010). Leadership in organizations. Upper Saddle River, New Jersey: Prentice Hall.

Zhang, Z., Jia, M., \& Gu, L. (2012). Transformational leadership in crisis situations: evidence from the People's Republic of China. The International Journal of Human Resource Management, 23(19), 4085-4109. 